\section{Design-Build \\ Studio Outcomes: \\ Researching Potential vs Practice}

Emilie Taylor Welty

Tulane School of Architecture

Albert and Tina Small Center for Collaborative Design

\section{Ann Yoachim}

Tulane School of Architecture

Albert and Tina Small Center for Collaborative Design

\section{Austin Hogans}

Tulane School of Architecture
"Architectural education, in the traditional setting of the classroom, is limited in its effectiveness. The design build programs offered during my time at Tulane School of A rchitecture both supplemented and extended the reach of my traditional architecture education. I cannot overstate the positive impact those programs - and the practicing professors who taught them

- had on me as a designer" -anonymous alumni survey participant

Academic design-build programs offer a method of teaching that outperforms conventional architecture pedagogy. Design build learning outcomes including those focused on complexity and collaborative problem solving offer transferable lessons that young designers can take with them into the profession. This is a baseline assumption our university's community design center has operated under for fourteen years, an assumption based on academic writings, antidote, and personal experience. With hundreds of alumni now in practice, we used a web-based survey instrument to test these assumptions and assess the outcomes of the design-build mode of education.

\section{BRIEF HISTORY OF DESIGN BUILD IN ARCHITECTURAL EDUCATION}

Design-build in A merican universities has early roots in the late nineteenth century when universities including Tuskegee Institute's architecture program combined design build pedagogy with pragmatic campus facilities needs and expanded that method of learning by doing to create thousands of school buildings across the rural south ${ }^{1}$. Decades later (1933-1957) Black Mountain College and their embrace of learning through doing was influenced by Bauhaus emigres who moved to A merica after the closing of the school in Weimar Germany². After the college's closing those influences reverberated in Yale's School of Architecture and led to the creation of the Yale building project (now the Jim V lock First Year Building Project) founded in 1967.

Twenty-six years later Auburn's Rural Studio began working in the rural south expanding on the social aims and scale of existing design build programs and in the process inspired a p roliferation of design build studios across North American schools of Architecture $^{3}$. While once viewed derisively by traditional academics as something akin to vocational training ${ }^{4}$, c urrently there is broader agreement in the value of design build as an educational tool, as evidenced by the explosion of design-build offerings at schools of architecture ${ }^{5}$. 
While these design build programs focused on 'learning through making' vary greatly in their project scales, programs, sites, timeline, methods of delivery, research agendas, and just about any other conceivable category, most of them share core pedagogical aims ${ }^{6}$ :

- Inform design through making

- Understand how to execute a p roject from s ketch to reality

- Understand tolerance, material, a nd connections at a 1:1 scale

- Empower students by broadening their experience and skill set ${ }^{7}$

- Cultivate collaboration and communication in the design process

- Provide an introduction to professional practice issues such as: project planning, funding acquisition, clients, liability, and the physical realization of design p roducts for use by actual users ${ }^{8}$.

Design-build offers a way to shift educational paradigms beyond the Beaux Arts studio based model to expand the classroom out into the world, expose students to the physical and material implications of what they draw and in many programs allows students to engage with topics of social responsibility - expanding the scope and relevance of design. All together design build studios offer a radical break from traditional teaching methods that have caused us to rethink all aspects of the design studio framework and provided the opportunity to be 'subversive leaders and teachers" in the classroom as we shape the next generation of p rofessionals.

\section{DESIGN BUILD AT TULANE SCHOOL OF ARCHITECTURE}

At Tulane's School of Architecture, these student focused aims of the design build studio have been combined with a d esire to make design services accessible to those who are underserved by the profession. We live in a c ity which suffered a l arge flood following hurricane Katrina in 2005 and endured subsequent years of planning meetings and charrettes which 14 years later have produced few tangible outcomes ${ }^{10}$. As frustrated community members and designers we've focused our energies on deeper, more collaborative forms of engagement in the design process, and on built outcomes goals that we often address through the design build studio model. Our pedagogy is grounded in the belief that design excellence and community engagement are not mutually exclusive.

We believe an engaged design process can serve as a capacity and coalition builder and is essential for students to not only understand broader social, economic and policy issues that shape the built environment, but also the power they have as architects to address them ${ }^{11}$. This pedagogy also serves as an opportunity for students to understand that the technical design skills they are learning are only one set of expertise and that all parties to a project bring unique skills and expertise to bear. We see design-build studios not as replica of practice $^{12}$, but as a m essy and ideal way to expose students to the ability of good design to positively shape place and conversations and as a w ay to expand their own social skills as they understand their agency and role in changing the built environment.

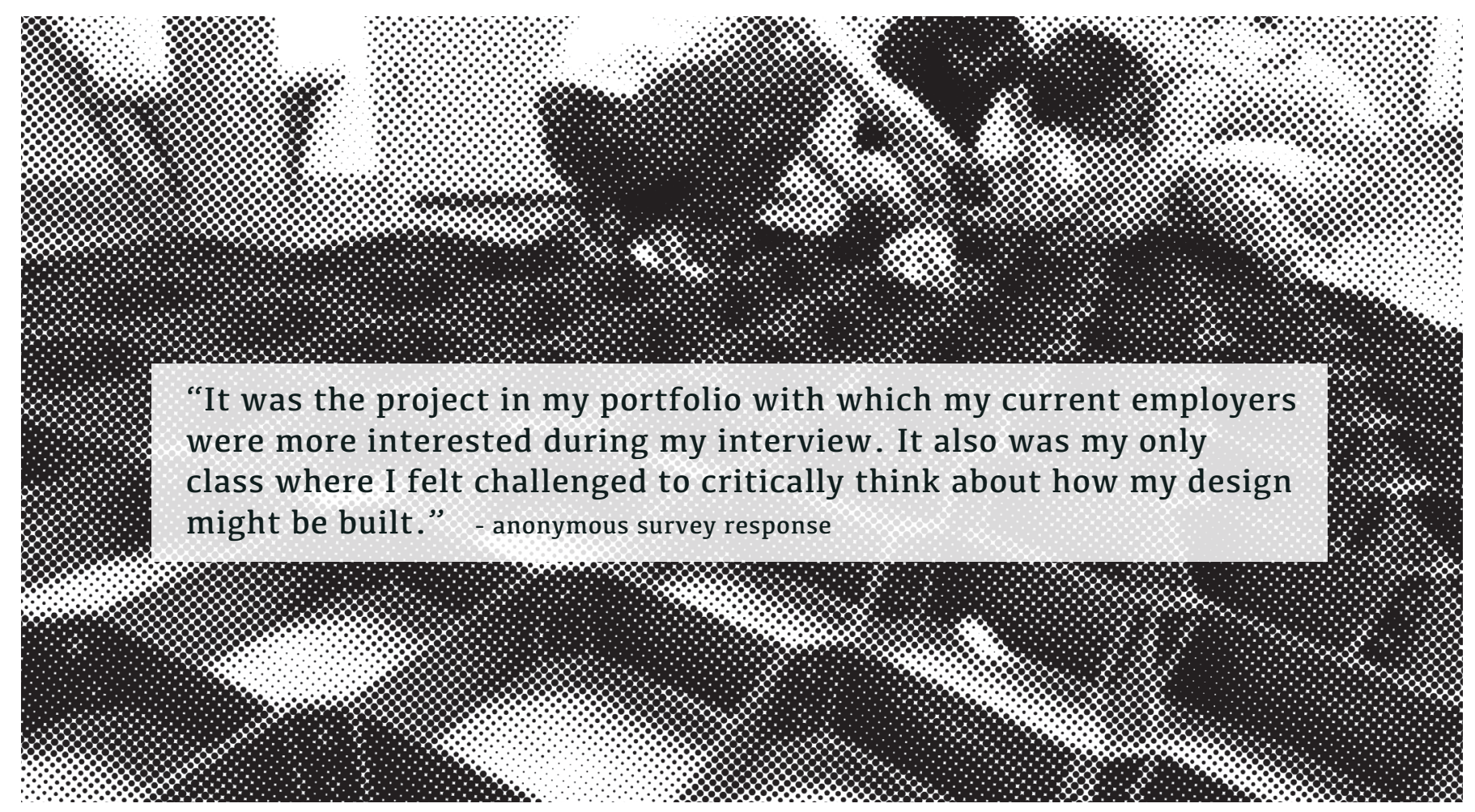

Figure 1. Anonymous survey response. 


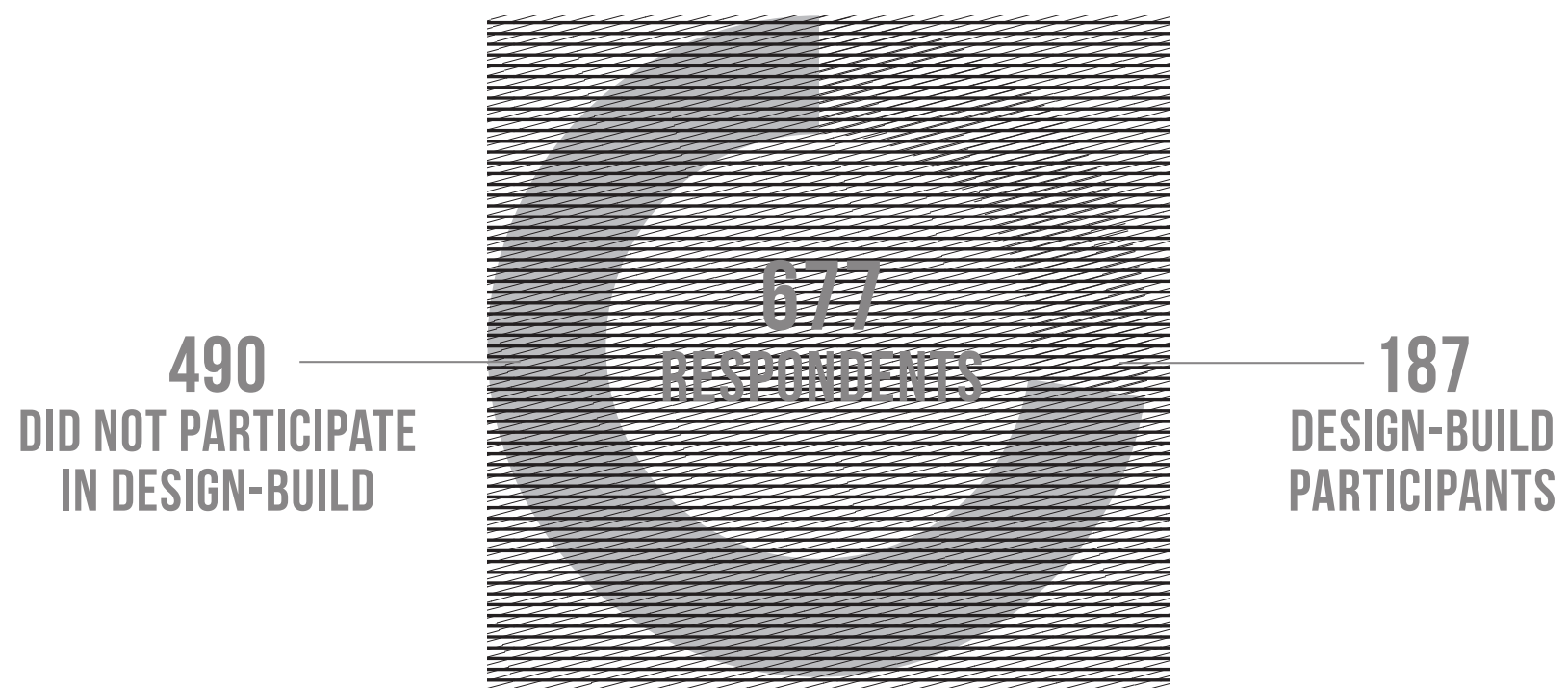

Figure 2. Alumni survey respondents breakdown.

Design build at Tulane takes three main forms:

1) Co-curricular Programs - Architects Week a weeklong student takeover of the school that has been running since the 1960's. Not all years include a design build component, though some have involved small scale temporary installations. Sukkah Design/ Build- a yearly event that began in 2008 where faculty and students partner with Tulane Hillel in to build contemporary sukkah structures to celebrate Sukot.

2) Small Center studios - semester long studio design-build projects run out of the Albert and Tina Small Center for Collaborative Design. This program has been offering design build courses since 2006, primarily through small scale public projects such as pavilions, interiors, gardens, and skateparks.

3) URBANbuild - a two-semester residential design build studio focused on designing and building housing prototypes primarily in New Orleans' Central City neighborhood. This program has been operating since 2005 and focuses on design and permitting in the first semester followed by the build in the second semester.

\section{THE SURVEY BASICS}

We hypothesize that design build learning outcomes including those focused on complexity and collaborative problem solving offer transferable lessons that young designers can take with them into the profession. To test this hypothesis, we conducted a webbased anonymous quantitative survey of School of Architecture alumni. The survey was distributed via email to the alumni listserv and promoted via the social media platforms (Facebook, Twitter,
Instagram) of the School of Architecture. The survey includes o pen ended, likert scale, and closed questions and totals 45 questions. Average length of time to complete the survey was five to seven minutes. The survey asked demographic data including graduation year and gender identity as well as content specific questions. These questions included those focused on the role of design build education on career trajectories, assessment of confidence gained in studio as well as other outcomes including continued involvement in hands on making and current civic participation.

The survey was sent out to 3,500 alumni and 677 responded yielding a $20 \%$ response rate (our goal was $n=750$ ), which has a +/-3.5\% margin of error. Of the respondents, 187 participated in design build projects ( 89 female, 97 male, 1 non-binary). Our two curricular design build programs have been in existence for 14 years. We estimate 525 unique students have participated in these intensive projects and 145 of the 187 respondents who participated in design build graduated in the years following these programs' creation.

\section{KEY TAKEAWAYS}

\section{1) Overwhelming recognition of value of design build} experience by people who participated

98\% of those respondents who participated in design build projects thoughts that it was an effective part of their architectural education.

2) Overwhelming recognition of value of design build experience by people who can hire

Additionally, $98 \%$ of those who participated in design build and have the ability to hire said that design build 
experience is an effective part of architectural education. This striking response rate could be due to selection bias wherein those people who have had an experience value it more in others. Yet a similar question was asked to all alumni (design and no-design build experience) and of those with the authority to hire $70 \%$ responded that design build experiences are moderately or extremely important to a candidate's resume. In fact, a majority of design build participants, $83.5 \%$, include that work in their portfolios as they apply for positions post graduation.

\section{3) Alumni report that design build experiences have influenced their career trajectories}

$70 \%$ of design build participants also reported that their experience with a design build project influenced their career trajectory. As researchers we thought that there would be a significant gender difference in influence of design build trajectories based on a previous related survey out of the University of Colorado Boulder ${ }^{13}$. What we found was less difference between men and women in the design build experience and its effects on non-traditional career trajectories than we had suspected.

\section{4) Parsing aspects of the academic design-build experience}

"initially it taught me the importance of detailing and allowed me to visualize how my drawings can be interpreted for better and worse on site. Since graduating, it has given me hands on experience that allows me to communicate with contractors and clients in a clear and concise manner. It also allowed me to build confidence in my ability to draw and create objects in the real world. I use those skills everyday whether I'm working on construction d ocuments or designing and building an art piece for a client." - anonymous alumni survey participant
The value of this design build pedagogy and insights to its impact can be seen in the comments submitted by alumni when we asked "Is there anything else you would like to share about your TSA design build experience?" Alumni shared that they learned the importance of getting uncomfortable, gained valuable communication skills and an understanding of the importance of the client/architect relationship. They also have shared that the project management and fabrication skills gained in design build studios helped jump start their career by setting them a part in the initial job search. The introduction to alternative modes of practice led alumni to recognize the potential of non-traditional career paths. It was previous testimonials ${ }^{14}$ that prompted and served as the foundation for this question. Furthermore, we attempted to parse out the different aspects of professional practice that design-build was most helpful in preparing alumni for. Figure 4 shows the percentage of design build alumni who responded yes to each question. The response bar percentages are further broken down by gender to understand how men and women respond differently to e ach learning outcome.

\section{5) Alumni show sustained efforts in making}

Of those who participated in design-build courses we asked if they have fabricated anything before the studio/project and 52\% had, while asking who has fabricated anything since. 70\% (125 of 177) have - further breaking that down by gender $60 \%$ of females, $79.5 \%$ of males have continued to make post-graduation.
Question: Do you think designbuild is an effective part of architectural education? $(\mathrm{n}=187)$

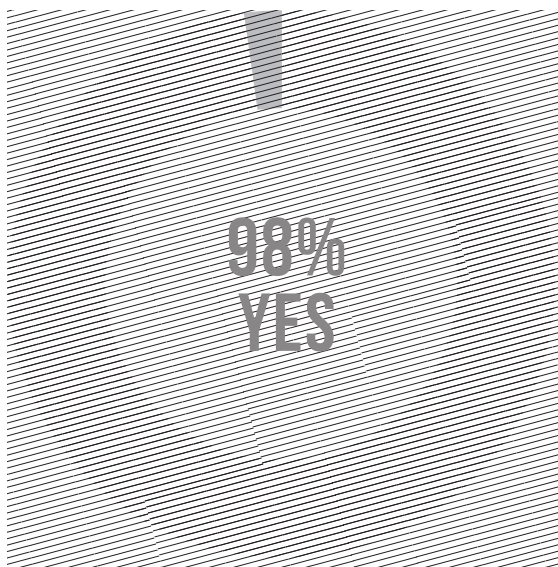

Question: Are design-build experiences an asset to a candidate's resume? $(\mathrm{n}=261)$

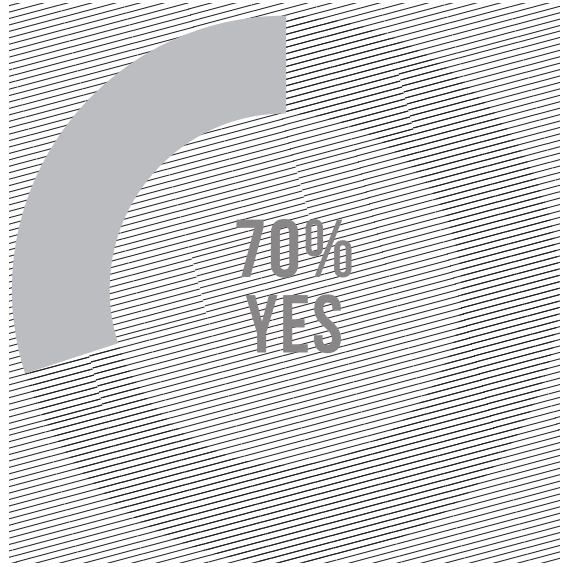

Question: Do you include designbuild studio work in your portfolio? $(n=187)$

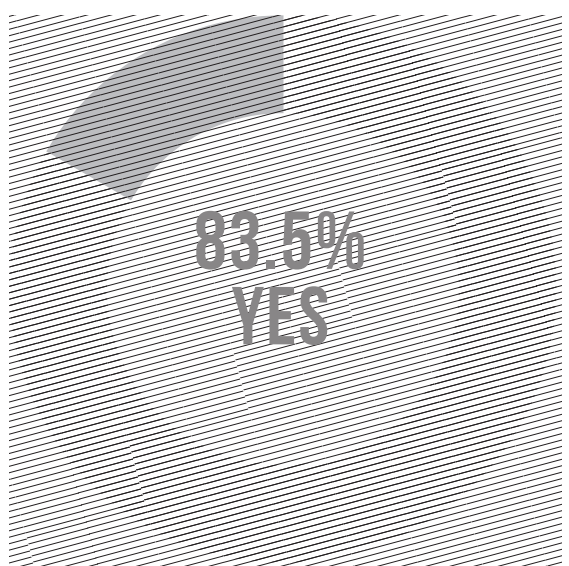

Figure 3. Understanding the value of design build experience. 
Question: Did participating in a design build studio help you...?

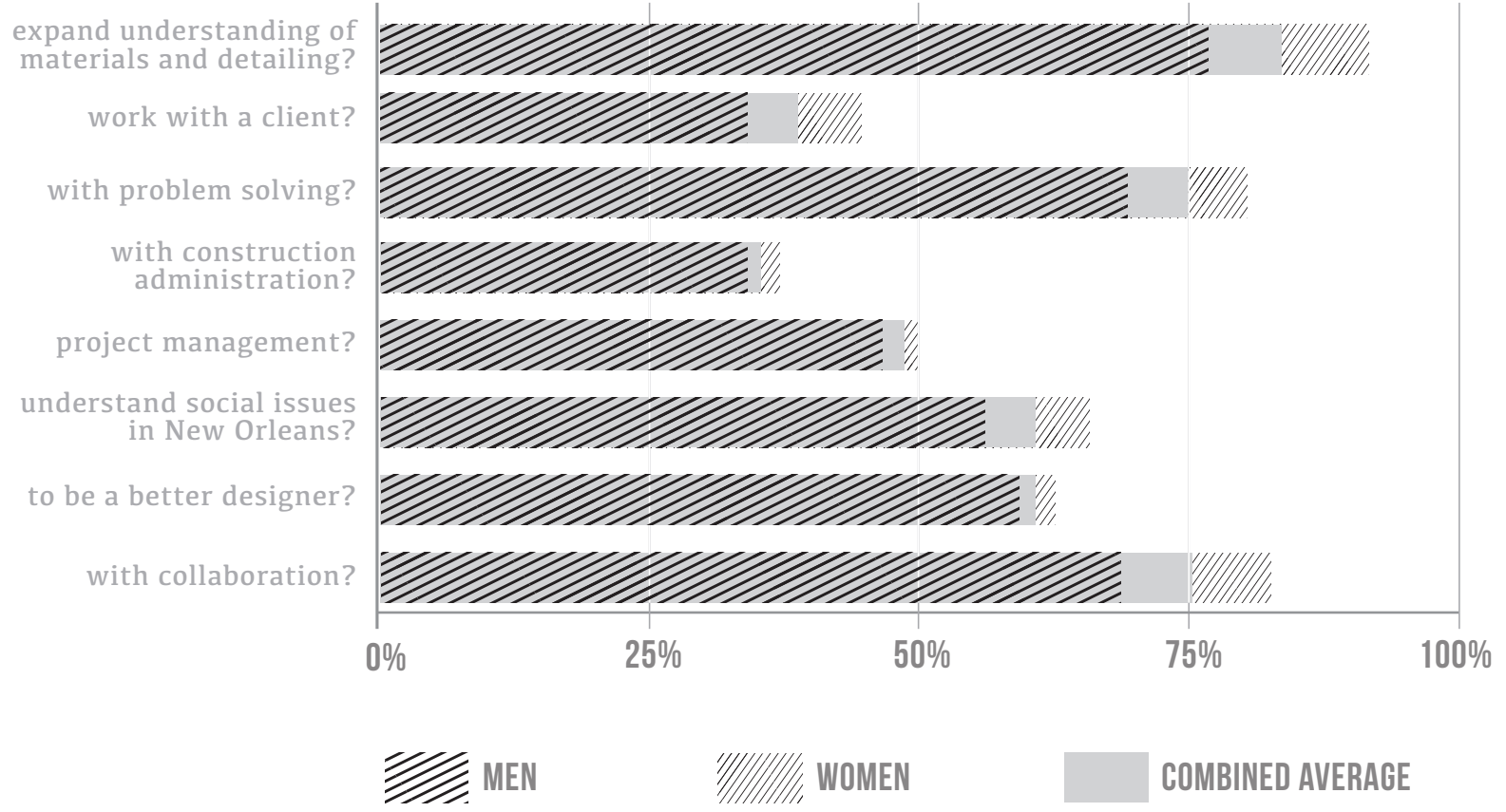

Figure 4. Understanding which aspects of professional practi e design build experience helps prepare students for. Bars show what percentage of respondents answered affir vely to each prompt. Hatching provides further informa on on how respondents answered by gender.

\section{ADDITIONAL TAKEAWAYS}

In addition to the yes/no and weighted questions we asked in the survey, individual written responses to open questions revealed further themes worth mentioning. The first is that design-build courses and programs serve as a powerful recruitment tool for the school.

"Tulane School of Architecture's design build programs are what attracted me as a g raduate student. I w anted to w ork directly with the community as an architect. In practice, Tulane game me the confidence to stand up for what I beleive in and pursue the projects I am passionate about. Equally important, TSA also provided a critical lens in which to view social justice or human centered design."

- anonymous alumni survey participant

Alumni also reported that design build served as a preparation for the non-design aspects of the profession and prepared them to be better architects, as seen in the following submissions:

"Design build gave me an edge as well as confidence when thrown into leading a construction administration portion of a project"

"I think design build provided me with a better understanding of collaborating with a project team, construction detailing, and on-site problem solving."
"Made me a better architect all around and I am more knowledgeable in technical aspects and communication skills with contractors than my peers."

\section{UNANTICIPATED RESEARCH OUTCOMES}

"The (design build) experience has been integral informing my view of architecture as a m eans of social justice"

Given that our two main design build programs were born in the wake of a disaster and their content, partners, and sites have engaged in questions of equitable recovery, affordability, and access to design services, we sought to understand what the impact of a p edagogy with an implicit commitment to engagement and equitable design process that reflects a socio-political and/or eco-cultural agenda on the next generation of professionals? The results were not what we anticipated. Nearly all respondents (95\%) report being aware of the social issues facing their current community and 62\% report personally playing a role in trying to address these issues. When we further parse that out to understand if those who participated in design build are more pro-active in addressing the issues that face their community, we found that $59 \%$ of design builders report proactive responses while $64.5 \%$ of non-design build alumni say they were actively addressing issues in their community. While we had hoped that an experience in making paired with themes of social justice would translate to more agency and action in our alumni 
it seems that they are slightly less proactive than their traditional studio peers - however, it should be noted that a majority of the design build respondents are in their first 10 years of their career path which may be a factor in how and if they have time to engage in their community's issues.

"I attended Tulane knowing I did not want to practice architecture in the traditional sense. The design+build experiences I had allowed me to see more clearly what an alternative path may look like and gave me a good foundation to ultimately start a youth design+build program that provides similar opportunities to young people in New Orleans." - anonymous alumni survey participant

As a research team we also suspected that exposure to design build in a university setting would make people more inclined to pursue non-traditional career paths. The survey results disprove that assumption with $74 \%$ of design build participants working in architecture firms while o nly $49 \%$ of those who did not participate in design build work in architecture firms. A ge and retirement may play a role in the large difference in these numbers. Data of recent graduates (post 2005) who participated in design/build indicate that $80 \%$ (116 of 145 ) are working in firms.

Likewise, we hypothesized that design build students would be more likely to work for small firms since often those firms can be more nimble and hands on in some ways, if New Orleans firms are any indication. That was certainly not what the data showed. Very few design build alumni are working in small firms, only $14 \%$, with $40 \%$ working in large firms of $60+$ people $(n=138)$, while nondesign build participants work for small firms at a rate of $32 \%$ and
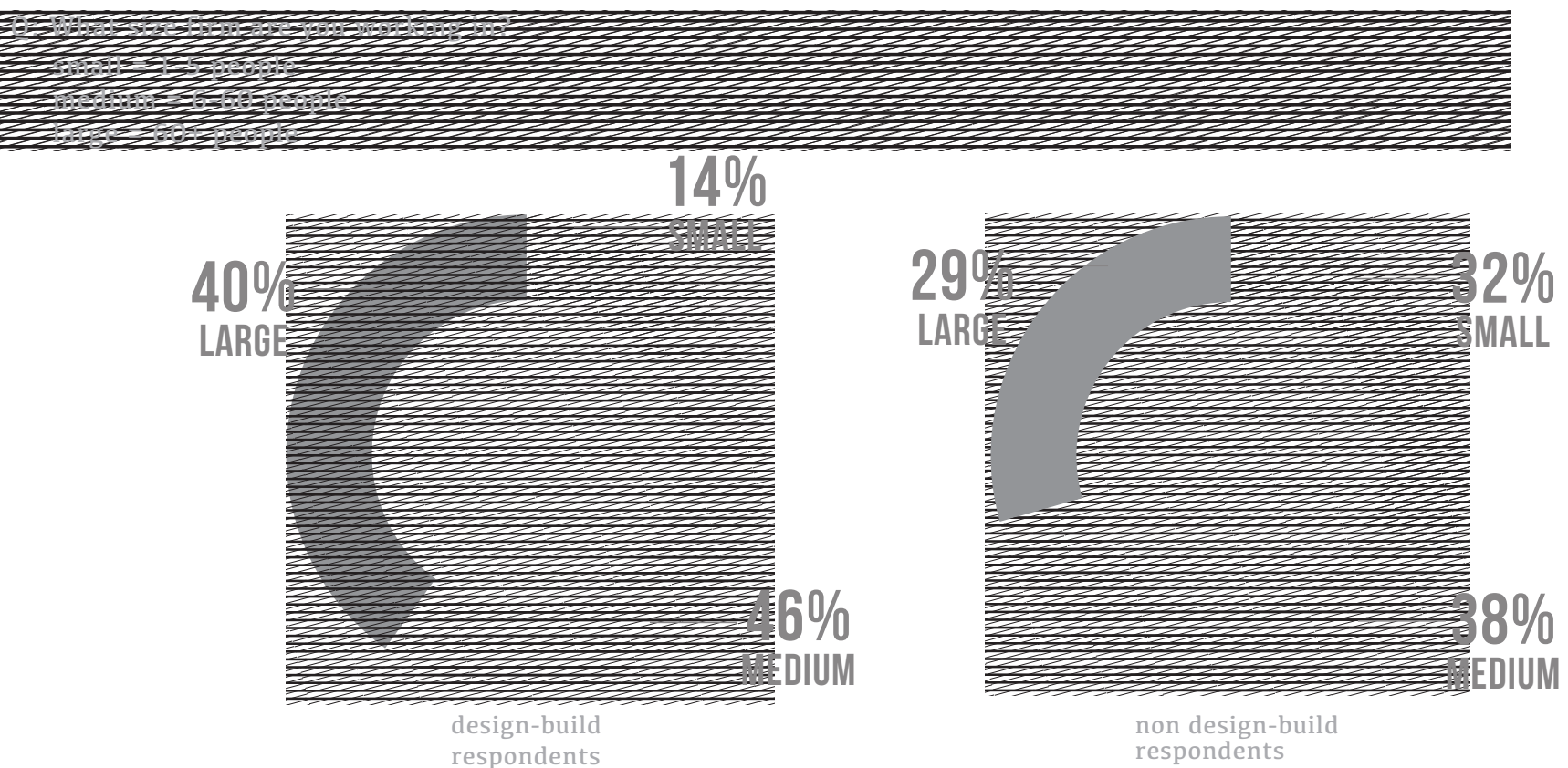

Figure 5. Understanding design build participation and how it impacts

professional trajectories 


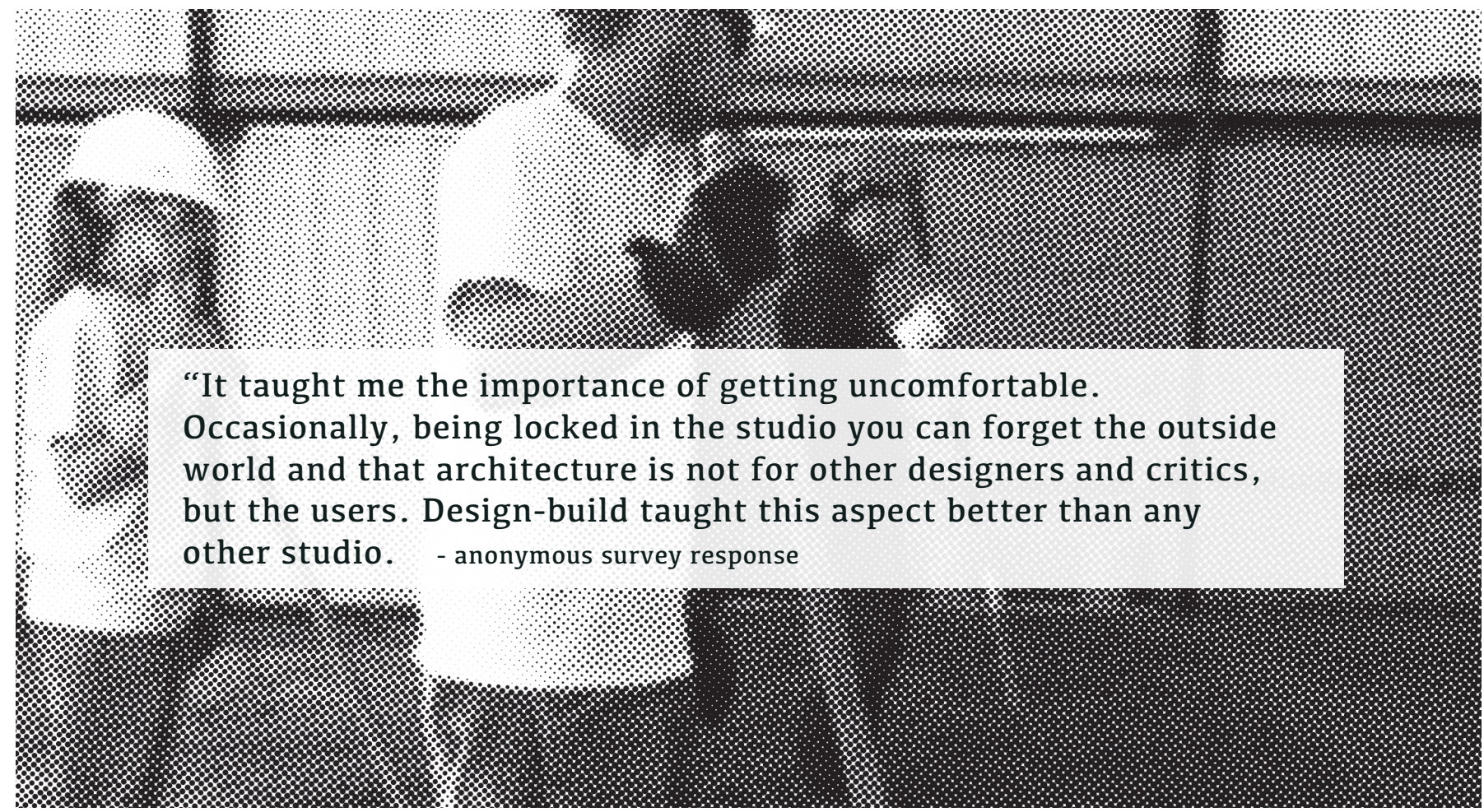

Figure 6. Anonymous survey response.

\section{CONCLUSION AND FUTURE STUDY}

As architectural education evolves and engages with challenges ranging from climate change to social inequity, there is continued importance in understanding the impact of design build e ducation as faculty consider how to imagine new futures where craft, fabrication and speculation a re connected with the development of individuals and growth of socially conscious designers. The growth of design build curricular offerings provide an o pportunity for architectural education to assess impacts of pedagogy and how learning outcomes are translating to professional practice. This survey was an initial attempt at that assessment.

Moving forward, the authors recognize the value of deeper analysis of existing data in particular exploring generational differences as well as specific design build experiences. More in depth key informant interviews and a f ocused quantitative survey could provide additional insight into the nuances of civic engagement involvement post-graduation and alumni understanding of social justice. Study results indicate that design build experience is of value to employers and recent graduates with design build experience work in professional practice at a higher rate than their peers. Our hope is that these results increase recognition that studios with contemporary agendas that re-think the normative studio's a pproach to collaboration, projects, and making as a m eans of learning offer invaluable professional skills transferable to p ractice. Furthermore, based on data showing more design-build alumni entering the profession than those without design build experience we speculate this form of e ducation provides students an expanded understanding of how they can play a role in the profession.

\section{Notes}

1. Goodman, Anna Gloria. "Citizen Architects: Ethics, Education and the Construction of a Profession, 1933-2013" PhD diss., University of California, Berkeley, 2005.

2. Hinson, David. "Community Centered Design/Build Studios: Connecting the Past and the Future of Architectural Education", (2002) ACSA Technology Conference.

3. $70 \%$ of ACSA participant schools' curriculum include Design-Build courses according to the introduction to Paper Proceedings from ACSA Fall 2014 Conference, Working Out, Thinking While Building

4. For a summary of other predecessors to the modern day design build studio teaching method and institutional and collegial resistance see: Canizaro, Vincent B. "Design-Build in Architectural Education: Motivations, Practices, Challenges, Successes and Failures", International Journal of Architectural Research, Volume 6 - Issue 3 - November 2012

5. An additional indicator of interest and emerging scholarship in the topic can be seen in ACSA conference submission rates. The Fall conference head in Nova Scotia focused on the topic of design-build had nearly double the number of 
submissions as each of the preceding 3 years had. (http:// www.acsa-arch.org/programs-events/conferences/ conference-acceptance-rates)

6. "Grounded in the realities that may include the site, setting, clients, schedules, budgets, and technical demands of construction, design decision-making is made more informed and responsive. Such training, it is assumed, will result in more informed and responsive future architects. And while construction is common to all, each program adopts the design-build pedagogy for their own reasons that can range from community service, experimentation with digital delivery methods, to various forms of 'building speculation'" from Canizaro, Vincent B.

7. Hailey, Charlie. Design/Build with Jersey Devil: A Handbook for Education and Practice Architecture Briefs. 2016

8. Gjertson, Geoff W. and Christopher D. Trumble. "Design-Build Gone South". Working Out; Thinking While Building (2014) ACSA Fall Conference Proceedings

9. Mockbee, Sam. Sarah Wigglesworth and Jeremy Till, editors, Architectural Design: The Everyday and Architecture (Academy Press, 1998)

10. Carey Clouse and Zachary Lamb, "Post-Crisis: Embracing Public Service Architecture with Humility." Journal of Architectural Education. 67:2. (2013), 186-194.

11. For and expanded explanation of our process see Taylor, Emilie "Refining Process, Expanding Practice: Public Interest Design Fieldnotes from the South" (2018) ACSA National Conference Proceedings

12 A critique of the common myths of academic design build can be found in Doyle, Shelby and Whitehead, Rob, "The Lore of Building Experience: Deconstructing Design-Build” (2017). Architecture Conference Proceedings and Presentations. 107.

13. Jade V. Polizzi, "Design-Build: A Vehicle for Self Discovery." Working Out; Thinking While Building (2014) ACSA Fall Conference Proceedings

14. Alumni of our Small Center program were interviewed for a Featured Alumni Booklet published in 2018, which can be downloaded at small.tulane.edu 